\title{
Symptomatic zinc deficiency in experimental zinc deprivation
}

\author{
C M Taylor, H F Goode, P J Aggett, I Bremner, B E Walker, J Kelleher
}

\begin{abstract}
An evaluation of indices of poor zinc status was undertaken in five male subjects in whom dietary zinc intake was reduced from $85 \mu \mathrm{mol} \mathrm{d} d^{-1}$ in an initial phase of the study to $14 \mu \mathrm{mol} \mathrm{d}^{-1}$. One of the subjects developed features consistent with zinc deficiency after receiving the low zinc diet for 12 days. These features included retroauricular acneform macullo-papular lesions on the face, neck, and shoulders and reductions in plasma zinc, red blood cell zinc, neutrophil zinc and plasma alkaline phosphatase activity. Alcohol induced hepatitis, which was suspected in this subject, may have caused a predisposition to altered zinc metabolism and possible zinc deficiency which was exacerbated by subsequent zinc deprivation. The report supports the value of neutrophil zinc concentration as an indicator of poor zinc status.
\end{abstract}

\section{Case report}

A 33 year old man took part in a study of zinc deprivation involving an initial 15 day baseline period followed by a very low daily zinc intake of $14 \mu \mathrm{mol} .^{1}$ The aim of the study, which involved a total of five subjects, was to investigate the mechanisms of zinc homeostasis in response to a low dietary zinc intake ${ }^{1}$ and to undertake an evaluation of indices of poor zinc status including plasma, red blood cell and neutrophil zinc, and alkaline phosphatase activity in plasma and neutrophils. Ethical permission for the study was granted by the joint ethical committee of the Grampian Area Health Board and the University of Aberdeen. Written informed consent was obtained from the subject after the procedures, risks, and benefits of the study had been explained to him.

His dietary zinc intake, metabolic and biochemical data are summarised in the figure. He had an increased serum $\gamma$ glutamyl transferase activity $(286 \mathrm{IU} / \mathrm{l})$ at the start of the baseline period, and this fell progressively over the subsequent six weeks to $36 \mathrm{IU} / 1$. His blood film showed anisocytosis with a degree of macrocytosis and stomatocytosis. His previous dietary and alcohol intake are uncertain but on the basis of his previous occupation as a barman and evidence of resolving hepatitis and haematological abnormalities, it is suspected that he may have had an alcohol induced heptatitis.

After 12 days of zinc deprivation retroauricular acneform macullo-papular lesions developed which spread during the next two days to his face, neck, and shoulders. He complained of headache, tiredness, and a sore throat. His plasma zinc was greatly reduced $\left(2.7 \mu \mathrm{mol} \mathrm{l}^{-1}\right.$, local reference range 10.0-17.6 $\mu \mathrm{mol} \mathrm{l}^{-1}$ ). Neutrophil zinc fell from $0.96 \mathrm{nmol} \mathrm{mg}^{-1}$ protein to $0.56 \mathrm{nmol} \mathrm{mg}^{-1}$ protein (reference range $0 \cdot 71-1.80 \mathrm{nmol} \mathrm{mg}^{-1}$ protein). ${ }^{2}$ Plasma alkaline phosphatase activity (ALP) and red blood cell zinc also decreased, while neutrophil alkaline phosphatase increased. Plasma albumin concentration remained unchanged at $47 \mathrm{gl}^{-1}$ throughout the study (figure).

Zinc repletion was begun by adding zinc sulphate to the semi-purified diet to provide $86 \mu \mathrm{mol}$ zinc daily for five days and then $164 \mu \mathrm{mol}$ a day for a further 18 days. During this period the skin lesions improved as did most of the biochemical variables. Plasma zinc concentration, however, remained below the reference range.

\section{Comment}

Symptomatic zinc deficiency is rare even in individuals at risk of specific or general malnutrition, although disturbances of zinc metabolism ${ }^{3-6}$ and zinc responsive clinical features ${ }^{67}$ have been described in alcoholic liver disease. We suspect that the subject had an alcohol induced hepatitis which may represent a predisposition to altered metabolism and possible deficiency of zinc. This was exacerbated by subsequent zinc deprivation while synthesising new tissue, as is suggested by his weight gain and nitrogen balance.

The study lends weight to the importance of tissue synthesis to the induction of zinc deficiency. Our subject achieved a positive zinc balance and had an overall net gain of zinc during the zinc deprivation period $(74 \mu \mathrm{mol})$, whereas the subject who developed skin lesions in the study by Baer and $\mathrm{King}^{8}$ lost a total of $1120 \mu \mathrm{mol}$ zinc. As our subject was anabolic during the deprivation period, gaining $1.5 \mathrm{~kg}$ in 15 days, it is possible that he was unable to fulfil his zinc requirement for anabolism. Assuming that nitrogen balance represents net synthesis of protein, $76 \mathrm{~g}$ of the total weight gain during zinc deprivation was protein. Synthesis of this protein would require 36-93 $\mu \mathrm{mol}$ zinc (assuming that muscle contains $0.47-$ $1.22 \mu \mathrm{mol} \mathrm{zinc} / \mathrm{g}$ wet weight ${ }^{9}$ ) which is close to the amount of zinc he retained. Had the subject's body weight been stable, his zinc requirements would have been reduced and symptomatic zinc deficiency may not have developed. 


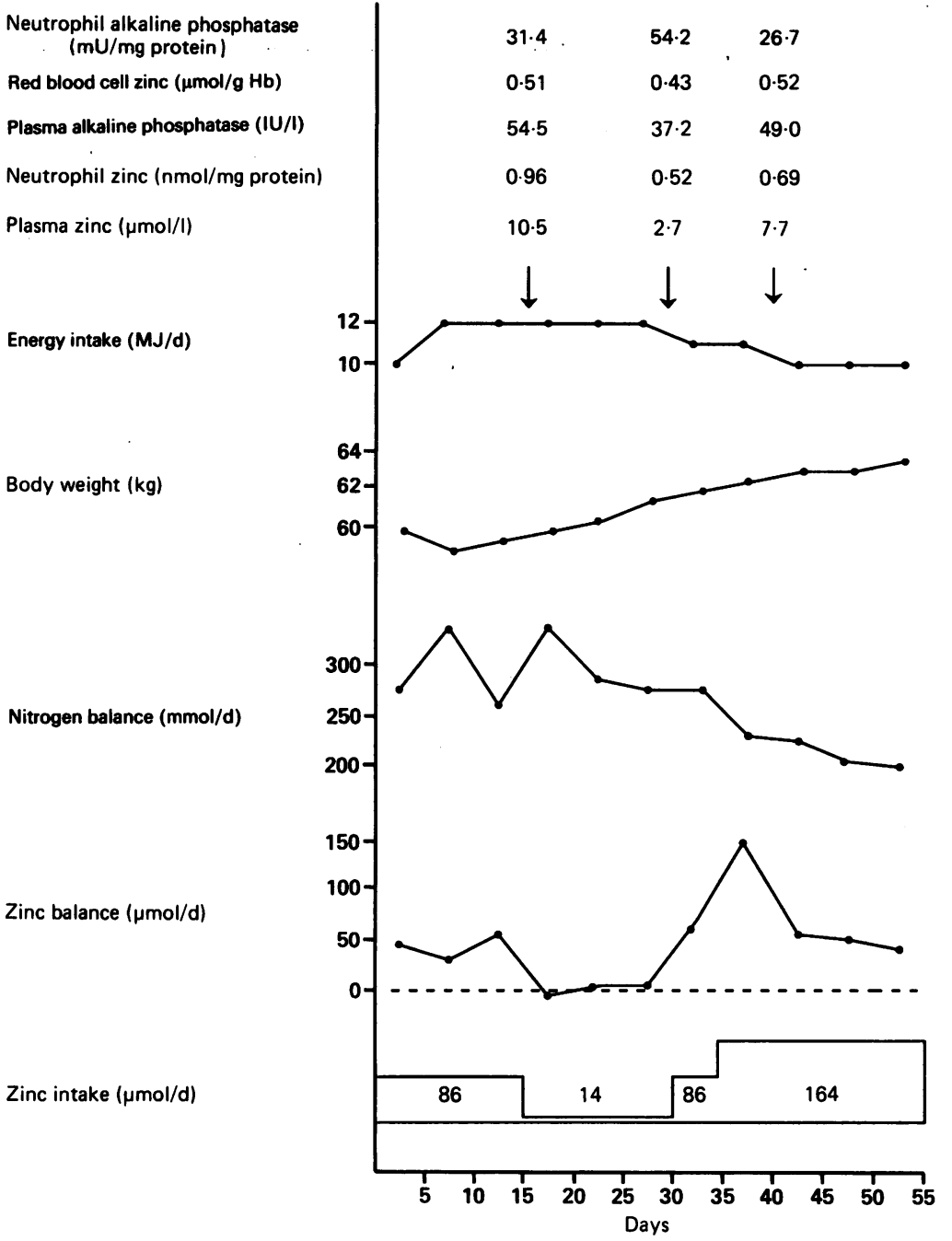

Dietary zinc and energy intake and biochemical data from a subject receiving a low zinc diet. damage, ${ }^{4}$ neutrophil zinc concentration is low only in more severe liver disease. ${ }^{13}$ This suggests that changes in neutrophil zinc concentrations in this subject were unlikely to have been due to suspected alcoholic hepatitis. A decrease in alkaline phosphatase in the plasma or serum has been reported in man, ${ }^{10} 14$ but increases in the neutrophils of rats. ${ }^{15}$ Decreased red blood cell zinc has also been observed in experimental zinc deprivation, ${ }^{1016}$ although other workers have not seen these changes. ${ }^{17} 18$

We thank Anne Bruce of the Human Nutrition Unit for her help in the recruitment and management of the volunteer and the staff of the Chemical Pathology and Haematology Department
Aberdeen Royal Infirmary for blood chemistry analysis.

This study was supported by the Scottish Education Department, the Medical Research Council, the Rank Prize Funds and the West Riding Medical Research Trust.

1 Taylor CM, Bacon JR, Aggett PJ, Bremner I. The homeostatic regulation of zinc absorption and endogenous losses in zinc deprived man. Am J Clin Nutr 1991;53:755-63.

2 Goode HF, Kelleher J, Walker B. Zinc concentrations in pure populations of peripheral blood neutrophils, lymphocytes and monocytes. Ann Clin Biochem 1989;26: 89-95.

3 Sullivan JF, Lankford HG. Zinc metabolism and chronic alcoholism. Am J Clin Nutr 1965;17:57-63.

4 Keeling PWN, Jones RB, Hilton PJ, Thompson RPH. Reduced leucocyte zinc in liver disease. Gut 1980;21: $561-4$

5 Mills PR, Fell GF, Bessane RG, Nelson LM, Russell RJ A study of zinc metabolism in alcoholic cirrhosis. Clin Sci study of zinc meta

6 Weismann K, Christiansen E, Dreyer V. Zinc supplementation in alcoholic cirrhosis. A double blind clinical trial. Acta Med Scand 1979;205:361-6.

7 Gaveau D, Piette F, Cortot A, Dumur V, Vergoend H. Manifestations cutanées du deficit en zinc dans la cirrhose éthylique. Ann Dermatol Venerol 1987;114:39-53.

8 Baer MT, King JC, Tamura T, Margen S. Acne in zinc deficiency. Arch Dermatol 1978;114:1043.

9 Fell GS. Diagnosis of zinc deficiency. In: Hambidge KM, Aggett PJ, eds. Zinc in human medicine. Proceedings of a symposium on the role of zinc in health and disease. Toronto: symposium on the role of zinc in health and

Skin changes of varying degrees have been described in other zinc deprivation studies 810 despite only marginal depressions of plasma zinc. The most characteristic clinical symptom of zinc deprivation, skin lesions, affect a tissue whose total zinc content is probably little changed by zinc deprivation. ${ }^{11}$ Skin constitutes about $16 \%$ of total body weight and contains up to $10 \%$ of total body zinc $(1.0-3.4 \mathrm{mmol} /$ $70 \mathrm{~kg})^{9}$ but has a slow turnover rate and could not act as a source of readily available zinc in the short term.

Our data support the suggestion that neutrophil zinc is an indicator of zinc deficiency ${ }^{1012}$ as neutrophil zinc decreased by $50 \%$ when the subject was deprived of this mineral. Although decreased leucocyte zinc concentrations have been reported in some patients with liver 